\title{
Brief Discussion on Selection of Flocculant in Sewage Treatment
}

\author{
Feng-li ZHOU ${ }^{1,}$, , Bo ZHANG (Corresponding Author) ${ }^{2, b}$ \\ 1,2Tianjin Research Institute for Water Transport Engineering, M.O.T., Tianjin 300456, China \\ aemail:17907419@qq.com, bemail:358539@qq.com
}

\section{Keywords: Sewage Treatment Flocculant PAC Ferric Chloride}

\begin{abstract}
The sewage treatment system adopts polymerize aluminum chloride (PAC for short) as a flocculant. In the process of selecting flocculant, various factors such as cost, operation, influent water quality, equipment and so on are comprehensively taken into account. A certain sewage treatment work has selected the most suitable agentia for sewage treatment system from many flocculants. In this article, the various types of sewage flocculants and their characteristics are briefly described, and the selection process of flocculants in a sewage treatment work is introduced, which is only for the reference of sewage treatment in the same industry.
\end{abstract}

\section{Introduction to the Types and Functions of Flocculants}

By using the positive (negative) group of its own to combine with some particles with negative (positive) electrical properties which are difficult to separate in water, the potential of the particles is reduced and the particles are in a stable state. These particles are concentrated by using their olymeric properties and separated by physical or chemical methods. The agentia used for this purpose is called flocculant.

Flocculant is one of the most widely used agentias in sewage treatment at present, which ffectively improves the sewage treatment rate and makes the sewage treatment efficiency more significant. locculation process is an indispensable key link in sewage treatment process. The addition of agentias can ensure the water quality after being treated by large sewage treatment equipment can meet the national discharge standard, effectively prevent the deterioration of water pollution status and ensure the sustainable development of ecological environment. There are many kinds of flocculants, from low molecular weight to polymer, from single type to composite type; the general trend is to develop toward the direction of cheap, practical, nontoxic and efficient.

Inorganic flocculant is cheap, but it has adverse effects on human health and ecological environment; although organic polymer flocculants with less dosage, less scum yield, strong flocculation ability, easy separation of alum floc, good effect of degreasing and suspended solids removal, residual monomers of such polymers have the "triple effect" (teratogenicity, carcinogenic, mutagenic), therefore, the scope of its application is limited; because of the absence of secondary pollution, microbial flocculant is easy to use and has an attractive application prospect. Microbial flocculants may replace or partially replace traditional inorganic polymers and synthesize organic polymer flocculants in the future. The development and application of microbial flocculant is in the ascendant, and its characteristics and advantages show a broad prospect for the development of sewage treatment technology.

\section{Development Trend and Application at Home and Abroad.}

2.1 Inorganic flocculant. Mainly divided into two large categories: iron preparation series and aluminum preparation series. Aluminum sulfate which was first developed by the United States is still in use today as an important inorganic flocculant. Most sewage treatment facilities in China basically adopt one or several of them. When Hong Kong Stonecutters Island Sewage Treatment Works was completed, it was one of the largest sewage treatment projects in Asia, with a daily treatment capacity of 1.7 million tons by using a chemically enhanced primary treatment process (CEPT process) and 
providing sewage treatment services to 3.5 million residents. This works chose ferric chloride binding polymer as flocculant and sludge dewatering agent, its dosage was only $10 \mathrm{mg} / \mathrm{L}$ of ferric chloride and $1 \mathrm{mg} / \mathrm{L}$ of polymer, and the removal of suspended solids efficiency reached $80 \%$. And the removal efficiency of biochemical oxygen demand has reached $70 \%$.

2.2 Organic polymer flocculants. It is a new type of wastewater treatment agent developed in the late 1960s. Compared with the traditional flocculant, it can exponentially increase efficiency, and the price is lower, so it has the trend of becoming the mainstream agentia step by step. Coupled with stable product quality, the production of inorganic polymeric flocculants account for $30 \% \sim 60 \%$ of total output of flocculants. The representative agentia, polyacrylamide (PAM) series, is specifically for the treatment of refractory wastewater and sludge dewatering. Because most of the organic polymer flocculants itself or its hydrolysis, degradation products are toxic, and the synthesis of acrylamide monomer is toxic, which can anesthetize the human central nervous system. The application field is limited, forcing the flocculant to develop in a direction of cheap and practical, non-toxic and efficient.

2.3 Compound flocculant. Compound flocculant dominates with numerous in variety and performance diversification, and the mechanism of action is mainly related to synergistic effects. Inorganic polymer composition adsorbed impurities and suspended particles, which resulted in the formation of particles and the particles gradually increased. Through its own bridging effect, the organic polymer composition can produce net capturing by using the active group adsorbed on the organic polymer and net capture the other impurity particles to sink together. Meanwhile, the existence of inorganic salts neutralizes the surface charge of pollutants and promotes the flocculation of organic polymer, which greatly improves the flocculation effect. Great progress has been made in the production and application of inorganic polymeric flocculants in China, and the most representative research on the polymerize aluminum chloride and polymeric ferric sulfate has been ranked the top in the world.

2.4 Microbial flocculant. Its commercial production began in 1990s, because there is no secondary pollution and easy to use, its application prospect is attractive. Such as Rhodococcus Erythropolis and NOC-1 made from it, are the best microbial flocculants that have been found so far. They have strong flocculating activity and are widely used in the treatment of livestock wastewater, expanded sludge and colored wastewater. The products of microbial flocculant in China have not been reported.

\section{Application and Equipment of Flocculant in a Certain Sewage Treatment Works}

The sewage treatment process of a certain sewage treatment works adopts the combination process of coagulation and advanced treatment of fiber rotary plate filter and uses PAC as flocculant to ensure the final effluent discharge with standard level. This process has been widely used in wastewater advanced treatment and reuses engineering, and has good treatment effect. Compared with the traditional advanced treatment processes such as activated carbon adsorption, continuous microfiltration and V-type filter, it has the advantages of low investment, low operating cost and high degree of automation.

Because the wastewater effluent after biochemical treatment COD, BOD and SS can not fully meet the new standard requirements due to large fluctuations in incoming water quality, so it is necessary to introduce a post-treatment system to ensure that the effluent quality reaches the standard. Through a large number of theoretical analysis and laboratory experiments, adding flocculant filtration is the most economical and effective measure, which can effectively remove SS and COD, etc. in wastewater. 


\section{Flocculant Selection and Experimental Data}

On the basis of the design theory verification of sewage treatment facilities of a certain sewage treatment works, additional experiments were added to ensure the reasonable selection of flocculant.

After selecting on the design basis of the coagulation tank, a certain sewage treatment works intends to use one of $\mathrm{FeCl}_{3}$ and PAC agents for flocculating setting to remove suspended solids. Two effect experiments were carried out on the main effect of flocculant: experiment 1, dosage and sedimentation time; experiment 2 , analysis and detection of water quality after treatment. The details are as follows.

\subsection{Experiment 1: Flocculant sedimentation experiment condition}

Sampling location: at present, the dosing position chosen for the process operation is the last case of V-301 effluent gallery, so the experimental sampling position is chosen in the second gallery from the bottom of the effluent, that is, the effluent without sodium hypochlorite and PAC.

Experimental water quantity: Respectively take $200 \mathrm{ml}$ water samples A and B from the samples collected, repeat the test three groups.

Experimental Methods: To simulate the current process conditions, the same amount of sodium hypochlorite was added to the two water samples respectively (the effect of sodium hypochlorite was to remove $\mathrm{NH}_{3}-\mathrm{N}$ in water, which was used as the control variable in this experiment). Then $\mathrm{FeCl}_{3}$ was added into $\mathrm{A}$ and PAC was added into B, and the mixture was stirred slowly and evenly.

Experimental phenomenon: when water sample $\mathrm{A}$ was added $4 \mathrm{ml} \mathrm{FeCl}_{3}$ on average, a small amount of fine floc began to appear and a large number of fine floc appeared at $8 \mathrm{ml}$. Floc failed to form a large alum floc and sedimentation rate was slow. Referring to the V-302 hydraulic retention time, after the solution was to be still standing for 5 hours, most of the flocs were still in suspension, the interstitial water was cloudy, and the whole solution turned yellow significantly.

When water sample B was added $12 \mathrm{ml}$ PAC on average, a small amount of fine flocs began to appear, and large flocs appeared when $16 \mathrm{ml}$ was dripped into the water sample, and the sedimentation rate was faster. Referring to the V-302 hydraulic retention time, after the solution was to be still standing for 5 hours, most of the flocs were settled to the bottom of the measuring cylinder, the interstitial water was clear and transparent, and the color of the whole solution was obviously superior to that of the water sample A.

\subsection{Experiment 2: Detection and Analysis on Sewage Water Quality after Flocculation Settling}

Routine water quality detection and analysis was carried out on the solution after experiment 1, including $\mathrm{pH}, \mathrm{SS}, \mathrm{NH} 3-\mathrm{N}$ and COD.

\begin{tabular}{|c|c|c|c|c|}
\hline Solution & $\mathrm{pH}$ & $\mathrm{SS}$ & $\mathrm{NH}_{3}-\mathrm{N}$ & $\mathrm{COD}$ \\
\hline $\mathrm{A}$ & 6.7 & 55 & 18 & 35 \\
\hline $\mathrm{B}$ & 7.1 & 43 & 10 & 28 \\
\hline
\end{tabular}

The experimental phenomena and results can provide some reference. According to the related literature and online data, it is found that the treatment effect of $\mathrm{FeCl}_{3}$ is better than that of aluminum salt in the treatment of low-temperature sewage or low-turbidity sewage. However, the sewage water condition treated by a certain sewage treatment works is high temperature and high turbidity sewage. Therefore, $\mathrm{FeCl}_{3}$ did not show the advantages of large flocs and fast sedimentation rate in the experiment. Taking into account the great corrosion of $\mathrm{FeCl}_{3}$ (can corrode copper), modulation and dosing equipment must use corrosion-resistant materials, most of the company's sewage treatment facilities adopt large-diameter buried pipeline, once the corrosion causes leakage, the future maintenance work will be very inconvenient. In comparison, the dosage of PAC is greater than that of $\mathrm{FeCl}_{3}$, but the treatment effect is better, the basicity is much higher than that of other aluminum salts, 
and the corrosiveness of iron salts is smaller. To sum up, the treatment effect of the company adopting $\mathrm{PAC}$ is better than the treatment effect of $\mathrm{FeCl}_{3}$.

\section{Conclusion}

In this article, the types, advantages and disadvantages of flocculants are briefly described, and the screening test of flocculants in a certain sewage treatment works is described briefly. The fundamental method of economic and stable operation of sewage treatment facilities is to select appropriate flocculant dosage through screening of flocculant, comprehensive consideration of treatment process, and the characteristics of the treated water body and its own operation characteristics.

\section{References}

[1] Luo Guyuan. Water Pollution Control Engineering. Higher Education Press. 2006

[2] He Manjun. Physical Chemistry Of Polymers. Higher Education Press. 2001

[3] Jiang Zhanpeng. Environmental Engineering. Higher Education Press.1992

[4] Zhou Yingqun, Gao Tingyao. Microbiology of Environmental Engineering. 2002

[5] Xu Xiaojun et al. Action Principle of Chemical Flocculant. Science Press. 2005 